\title{
Olfactory Receptor Neurons from Antennae of Developing Male Manduca sexta Respond to Components of the Species-specific Sex Pheromone in vitro
}

\author{
Monika Stengl, ${ }^{1}$ Frank Zufall, ${ }^{2}$ Hanns Hatt, ${ }^{2}$ and John G. Hildebrand ${ }^{1}$ \\ 'Arizona Research Laboratories, Division of Neurobiology, University of Arizona, Tucson, Arizona 85721 and 2 Institut für \\ Physiologie, Technische Universität München, W-8000 München 40, Germany
}

\begin{abstract}
Male-specific olfactory receptor neurons, dissociated from developing antennae of the moth Manduca sexta and grown in long-term primary cell culture, can respond to at least one component of the female moth's sex-pheromone blend with the opening of a nonspecific cation channel. This response does not require the coapplication of pheromone-binding protein.
\end{abstract}

Adult male sphinx moths, Manduca sexta, locate mating partners by detecting and orienting to the female's species-specific sex-pheromone blend. The female moth releases this volatile chemical signal from a gland at the tip of her abdomen (Eaton, 1986; Itagaki and Conner, 1988). Organic-solvent extracts of this gland contain a characteristic mixture of $12 \mathrm{C}_{16}$ and $\mathrm{C}_{18}$ aldehydes, including the predominant and most potent component, $(E, Z)$-10,12-hexadecadienal or bombykal (Starratt et al., 1979; Christensen et al., 1989; Kaissling et al., 1989; Tumlinson et al., 1989).

Male Manduca sexta respond to stimulation with bombykal and at least two other pheromone components via specialized olfactory receptor neurons (ORNs) innervating long, sexually dimorphic sensory hairs (sensilla trichodea) on the antennae (Sanes and Hildebrand, 1976a,b; Schweitzer et al., 1976; Kaissling et al., 1989; Keil, 1989). The pheromone components are assumed to bind to presumptive receptors in the dendritic membranes of the ORNs and thus to initiate a series of transduction processes. These processes finally lead to depolarizing receptor potentials, which initiate action potentials that encode information about the quality, quantity, and temporal pattern of the odor and carry it to the brain (Kaissling and Thorson, 1980; Kaissling, 1987). "Tip recordings" from cut trichoid sensilla on moth antennae have shown that, after pheromonal stimulation,

\footnotetext{
Received Sept. 26, 1991; revised Jan. 3, 1992; accepted Jan. 17, 1992.

We thank Deborah Sakiestewa and Dr. H. Wieczorek for providing insects; Drs. Jon Hayashi and Lynne Oland for supplying conditioned medium; Drs. Thomas Christensen, Marcie Glicksman, Eric Hanneman, Sue Kinnamon, and Richard Levine for advice and encouragement; and Drs. Jon Hayashi, Uwe Homberg, Richard Levine, Lynne Oland, and Leslie Tolbert for valuable comments on the manuscript. We are also grateful to Charles Hedgcock, R.B.P., for excellent photographic assistance, Prof. H.-J. Bestmann and Dr. James Tumlinson for providing bombykal; Drs. J. Buckner and J. Svoboda of the U.S. Department of Agriculture for generously providing $M$. sexta eggs; D. Beyer, W. Zeitz, and Birgit Preibisch for expert technical assistance; and Pamela Murray for administrative assistance. This work was supported in part by NIH Grant AI-23253 to J.G.H.

Correspondence should be addressed to Dr. John G. Hildebrand, ARL Division of Neurobiology, 611 Gould-Simpson Building, University of Arizona, Tucson, AZ 85721.

Copyright (C) 1992 Society for Neuroscience $0270-6474 / 92 / 122523-09 \$ 05.00 / 0$
}

odor-dependent potential changes occur (Kaissling, 1987). These extracellularly measured receptor potentials rise rapidly until they reach a plateau and then repolarize gradually. The rapid rise is accompanied by a decrease in resistance and by a phasic, phasic-tonic, or tonic spiking response (Schneider, 1962; Schneider and Boeckh, 1962; Zack-Strausfeld, 1979; Kaissling and Thorson, 1980; Kaissling, 1986, 1987; Zack-Strausfeld and Kaissling, 1986; Kaissling et al., 1989). In response to strong pheromonal stimuli, both the extracellularly recorded receptor potential and the impulse frequency decrease as a result of adaptation (Zack-Strausfeld, 1979; Zack-Strausfeld and Kaissling, 1986; Kaissling et al., 1987).

The transduction processes that underlie these adapting receptor potentials in moth sensilla are assumed to occur in the dendrites of the ORNs, in an unusual ionic environment. Within the hollow, hairlike cuticular sensillum, the dendrites are bathed by a receptor lymph containing circa $200 \mathrm{~mm} \mathrm{~K}^{+}$, circa $20 \mathrm{~mm}$ $\mathrm{Na}^{+}$, and presumably several micromolar $\mathrm{Ca}^{2+}$ (Keil, 1984; Grünert, 1985; Kaissling, 1986) as well as abundant soluble proteins, the pheromone-binding proteins (PBPs) (Vogt and Riddiford, 1981; Kaissling et al., 1985; Vogt et al., 1985; Klein, 1987; Györgyi et al., 1988; Raming et al., 1989, 1990). It has been proposed that these PBPs (in $M$. sexta, ca. $16 \mathrm{kDa}$; György et al., 1988) carry the lipophilic pheromone components through the aqueous receptor lymph and may be required for the recognition of the pheromone components by presumptive receptors in the dendritic membranes of the ORNs (Vogt et al., 1985; Vogt, 1987; van den Berg and Ziegelberger, 1991). Alternatively, the PBP may scavenge, and thus rapidly inactivate, the pheromone components after their interactions with receptor sites (Kaissling, 1986).

Because the ORNs are not readily accessible to intracellular or patch-clamp recording techniques in situ (Zufall and Hatt, 1991), we developed a primary-cell-culture system for studies of the mechanisms underlying the responses of male-specific ORNs to pheromone (Stengl and Hildebrand, 1990). Cultures are derived from antennae of stage 3 male $M$. sexta pupae, within $2 \mathrm{~d}$ after the mitotic birth of the ORNs and their associated cells.

Among the diverse cells found in these cultures, one particular type with a $5 \mu \mathrm{m}$ soma and fine processes has been correlated morphologically and immunocytochemically with ORNs in vivo (Hishinuma et al., 1988a,b; Stengl and Hildebrand, 1990). In situ morphological, immunocytochemical, and physiological studies indicate that about $35 \%$ of cells of this type are recognized by the monoclonal "male-olfactory-specific antibody" 
(MOSA) and are responsive to pheromone components (Sanes and Hildebrand, 1976a,b; Hishinuma et al., 1988a,b; Kaissling et al., 1989; Lee and Strausfeld, 1990). Patch-clamp studies show further that ORNs differentiate physiologically in vitro and acquire various types of ion channels in their soma membranes. After 3 weeks in culture, the ORNs express at least one type of $\mathrm{Na}^{+}$channel and at least three types of $\mathrm{K}^{+}$channels (Zufall et al., 1991b).

Here we demonstrate that cultured ORNs can respond specifically to extracts of the female sex-pheromone gland or to the synthetic pheromone component bombykal with opening of a nonspecific cation channel. Furthermore, addition of PBP is not required for these responses.

Preliminary accounts of some of this work have been presented elsewhere (Stengl et al., 1989, 1991).

\section{Materials and Methods}

Unless otherwise specified, all culture media were purchased from GIB$\mathrm{CO}$ (Grand Island, NY), and all chemicals and biochemicals, from Sigma Chemical Co. (St. Louis, MO).

Animals. Manduca sexta (Lepidoptera: Sphingidae) were reared from eggs on artificial diet (modified from Bell and Joachim, 1976) on a longday photoperiod regimen $(17 \mathrm{hr}$ light $/ 7 \mathrm{hr}$ dark $)$ at $25-26^{\circ} \mathrm{C}$ and 50 $60 \%$ relative humidity. Pupae were staged as previously described (Sanes and Hildebrand, 1976a; Tolbert et al., 1983). They were usually selected for dissection between 2:00 and 5:00 AZT (Arbitrary Zeitgeber Time, with lights on at 00:00 AZT) and anesthetized by chilling on ice for 10$15 \mathrm{~min}$ before dissection of the antennal flagellum.

Cell cultures. A detailed description of the culture techniques has been reported elsewhere (Stengl and Hildebrand, 1990). Briefly, antennal flagella from male $M$. sexta pupae (stage 3 of the 18 stages of adult development) were disrupted by a combination of mechanical and enzymatic treatments. The dispersed cells were plated in concanavalin A-coated or uncoated Falcon plastic dishes, in Leibowitz L15 medium, supplemented with $5 \%$ fetal bovine serum (Hyclone) and 20-hydroxyecdysone (ca. $1 \mu \mathrm{g} / \mathrm{ml}$ ) or conditioned medium (supernatant fluid from cultures of a non-neural $M$. sexta cell line, generously provided by Drs. J. Hayashi and L. Oland, of the ARL Division of Neurobiology, University of Arizona, or extracellular fluid from antennae) (Stengl and Hildebrand, 1990). The cultures were maintained for 2-4 weeks at about $30^{\circ} \mathrm{C}$ at high humidity in an incubator.

Immunocytochemistry. ORNs from which recordings had been obtained were stained for immunoreactivity to the male-olfactory-specific antibody (MOSA; Hishinuma et al., 1988a,b), as described previously (Stengl and Hildebrand, 1990).

Patch-clamp technique and data analysis. Patch-clamp recording experiments closely followed the methods described by Hamill et al. (1981) Patch pipettes were made from borosilicate glass capillaries (World Precision Instruments, GC. 150 T10; or Clark Electromedical Instruments, Reading, UK) with a two-stage electrode puller (DMZ, Zeitz Instruments, Augsburg, Germany) or a Sutter Instruments micropipette puller (model P80/PC). The pipettes were coated with Sylgard (Dow Corning, Midland, MI) and then fire polished. The tip resistance was 6-12 M $\Omega$ when the electrodes were filled with physiological saline solution. The cells were viewed at $320 \times$ magnification with a Zeiss Axiovert 10 inverted microscope equipped with phase-contrast optics or at $400 \times$ with an Olympus inverted microscope equipped with phasecontrast or Hoffmann modulation contrast optics. After formation of a seal between the pipette and the cell membrane, the electrode capacitance was compensated. During application of the pheromone, the membrane patches were kept at $0 \mathrm{mV}$ holding potential (at the cells' resting potential) in the cell-attached configuration.

Single-channel currents were measured at room temperature with an EPC-7 amplifier (List Electronic, Darmstadt, Germany) or an AxopatchIC patch-clamp amplifier (Axon Instruments Co., Burlingame, CA). The signals were recorded on videotape with a modified Sony PCM501-ES video recorder or with an instrumentation FM tape recorder (A. R. Vetter Co., Repersburg, PA) or acquired on line with an 80386 based microcomputer (Dell Computer Corp., Austin, TX) using pCLAMP software (Axon Instruments Co.). The data were analyzed with pCLAMP software (Axon Instruments) or with custom programs (Dudel and Franke, 1987). Single-channel currents were low-pass filtered at $2-5 \mathrm{kHz}$ with an eight pole Bessel filter and digitally sampled at $25 \mathrm{kHz}$ using a Hewlett-Packard P 9802 computer equipped with a Hewlett-Packard Multiprogrammer II interface. More detailed descriptions of the methods used can be found elsewhere (Dudel and Franke, 1987; Zufall et al., $1991 \mathrm{~b}$ ).

Solutions. For recordings, cells were kept in "extracellular saline solution" containing (in $\mathrm{mM}$ ) $156 \mathrm{NaCl}, 4 \mathrm{KCl}, 6 \mathrm{CaCl}_{2}, 5$ glucose, and 10 HEPES (adjusted to $\mathrm{pH} 7.1$, with $\mathrm{NaOH}$ ). The "intracellular saline solution" used to fill pipettes for the cell-attached recordings contained (in $\mathrm{mm}$ ) $150 \mathrm{KCl}, 5 \mathrm{NaCl}, 2 \mathrm{MgCl}_{2}, 0.1 \mathrm{EGTA}$ ( $\mathrm{pCa}=7$ ), and 10 HEPES (adjusted to 7.2 with $\mathrm{KOH}$ ). The final $\mathrm{K}^{+}$concentration was about 154 mM.

Extraction of pheromone glands and delivery of pheromonal stimuli. Sex-pheromone extracts were prepared by dipping female abdominal tips, isolated from adult virgins, in dimethyl sulfoxide (DMSO), dimethyl formamide (DMF), ethanol, or $n$-hexane. Freshly prepared for each experimental session, the "stock extract" consisted of $100 \mu \mathrm{l}$ of solvent in which five female abdominal tips had been dipped for $2 \mathrm{~min}$ each (Tumlinson et al., 1989). These stock extracts were diluted $1: 10^{3}$ to $1: 10^{5}$ in $1 \mathrm{ml}$ of extracellular saline solution. The hexane stock solution (which resulted in the purest pheromone extracts) was mixed with $10 \%$ DMSO, to facilitate aqueous solubility, before dilution in extracellular saline. The concentration of pheromone in dilutions of the stock extracts was estimated (as "bombykal equivalents") by means of electroantennogram (EAG) recordings, obtained with adult male antennae by established procedures (Christensen et al., 1989).

Diluted pheromone extract was applied via a glass-capillary pipette with a tip opening of $<10 \mu \mathrm{m}$, driven by a Picospritzer (General Valve Corp., Fairfield, NJ). The pheromone was puffed onto the cell's soma ( $\geq 20 \mu \mathrm{m}$ from the pipette tip) before or after formation of a seal between the pipette and the cell membrane, respectively, to allow or prevent direct access of the pheromone to the membrane patch. The final concentration of pheromone in the gland extracts used ranged between 3 fg and $30 \mathrm{pg}$ (bombykal equivalents) per $\mathrm{ml}$ (as estimated by means of EAG recordings), and the final concentration of the stock solution of synthetic bombykal (prepared from a $10 \mu \mathrm{g} / \mathrm{ml}$ DMSO solution of bombykal kindly provided by Prof. H. Bestmann) ranged between $100 \mathrm{fg}$ and $1 \mathrm{ng}$ per $\mathrm{ml}$. Usually the cells were first stimulated with solvent alone (control) and then tested with the pheromone solutions in the same solvent. Because the pheromone adsorbed to plastic or glass surfaces, the first application of pheromone contaminated the preparation dish. Once pheromone had been introduced into the dish, its physiological effect (thus possibly its effective concentration) could be reduced by addition of bovine serum albumin (BSA) and extensive washing, but the physiological responses of the cells indicated that the pheromone could not be completely removed from a contaminated dish.

Preparation of pheromone-binding protein. PBP was extracted by previously described methods (Klein, 1987; Vogt, 1987; Györgyi et al., 1988). Antcnnal flagclla $(n=44)$ of adult male $M$. sexta ( 1 d posteclosion) were collected over solid $\mathrm{CO}_{2}$. The frozen flagella were vortexed in pulverized solid $\mathrm{CO}_{2}$ to break off the sensory hairs. After the solid $\mathrm{CO}_{2}$ had fully sublimed away, the flagellar shafts were removed. The detached sensory hairs and scales were collected with diethyl ether. After evaporation of the ether, the fractions were taken up in $1 \mathrm{ml}$ of buffer solution containing $250 \mathrm{~mm}$ sucrose, $2 \mathrm{~mm}$ EDTA, and $50 \mathrm{~mm}$ Tris $(\mathrm{pH}$ 8 ) and homogenized on ice. The homogenates were centrifuged at 2000 rpm for $5 \mathrm{~min}$ in a Sorvall RC-5B centrifuge (Du Pont Instruments, Wilmington, DE), and the supernatant fractions for $10 \mathrm{~min}$ at 9000 $\mathrm{rpm}$. The resulting supernatant fractions were centrifuged at $27,000 \mathrm{rpm}$ for $1 \mathrm{hr}$. The membranous and cytoplasmic fractions were taken up in buffer, and the protein concentrations were determined with a modified Lowry assay (Peterson, 1977; data not shown). The fractions were electrophoresed on SDS-PAGE gels or on native $12 \%$ acrylamide gels (Vogt and Riddiford, 1981) and stained with Coomassie blue. The cytoplasmic fraction of the sensilla and scales contained two bands with a molecular mass between 14 and $21 \mathrm{kDa}$, corresponding to the published molecular mass of PBP (18 kDa). This fraction was used as PBP in physiological experiments.

\section{Results}

To test the ability of cultured ORNs to respond specifically to pheromone, we obtained patch-clamp recordings from cells in antennal-cell cultures 2-4 weeks old. Except for control recordings (see Control experiments, below) on various types of an- 
tennal cells, only ORN-like cells (i.e., with a $5 \mu \mathrm{m}$ soma and fine processes) were chosen for these experiments (Stengl and Hildebrand, 1990). The number of ORNs from which recordings were obtained successfully is given as $n$.

To obtain responses from intact cells without dialysis of cytoplasmic components such as second messenger systems, we recorded in the cell-attached mode from the cell soma. The pheromonal stimulus was applied either before or after formation of the seal between the patch pipette and the cell membrane. The pheromone was applied via a puffer pipette, either with or without PBP, to test whether addition of PBP is necessary to obtain pheromone-dependent responses. The stimulus concentrations varied between about $3 \mathrm{fg}$ and $30 \mathrm{pg}$ of bombykal per $\mathrm{ml}$ for the pheromone-gland extracts, as estimated by EAG recordings (Christensen et al., 1989) (see Materials and Methods), and varied between about $100 \mathrm{fg}$ and $1 \mathrm{ng}$ per $\mathrm{ml}$ for the synthetic bombykal solutions.

\section{Control experiments}

Cultured antennal cells were tested for responses to stimulation with the solvents alone. We also sought to determine whether the responses to pheromone were specific to pheromone components. Furthermore, we tested whether the cells respond at a specific time in vitro and whether the responses are specific to certain types of cells.

In more than 50 cell-attached patch-clamp cxpcriments, cultured ORNs were stimulated first with the solvents (DMSO, DMF, ethanol, hexane-DMSO) alone, before application of the pheromone sample. In none of these control experiments were responses elicited by the solvents alone. Cells that responded to pheromone did not respond to $1 \mu \mathrm{M}$ citral $(n=8)$, a potent plant-derived odorant. These findings suggested that the responses might be cell-type-specific.

None of the 15 nonreceptor cells (judged by morphological criteria) responded to pheromonal stimulation. To demonstrate that the cells we tested were male-specific ORNs, we processed cells ( $n=2$ ) that responded specifically to pheromonal stimulation for MOSA immunocytochemical reactivity. These pheromone-responsive cells expressed the male-specific antigen recognized by MOSA (data not shown), which is expressed in situ by mature male-specific ORNs (Hishinuma et al., 1988a,b). Because most tested cells detached from the bottom of the culture dish or shriveled up and died after prolonged stimulation with pheromone, we did not succeed in processing all pheromone-responsive cells for MOSA immunocytochemistry. Immature ORNs (1 week in culture), which do not exhibit MOSA immunoreactivity (Stengl and Hildebrand, 1990), did not respond to pheromone $(n=10)$.

\section{Specific responses to pheromone}

To investigate the responses of 2-3-week-old cultured ORNs to pheromone, we stimulated the ORNs with extracts of female pheromone glands while recording in the cell-attached configuration at the resting potential. The pheromone was applied either before or after formation of the patch-clamp seal. Specific responses to the female pheromone-gland extracts ( $n=48$ out of 127 ORNs from which recordings were obtained successfully) could be accounted for fully by the response to synthetic bombykal $(n=5)$. This finding suggested that the cells under study responded mainly or exclusively to bombykal in the extracts.

In these experiments, $38 \%$ (48 of 127) of ORN-like cells in 2-3-week-old cultures responded specifically to extracts of fe-

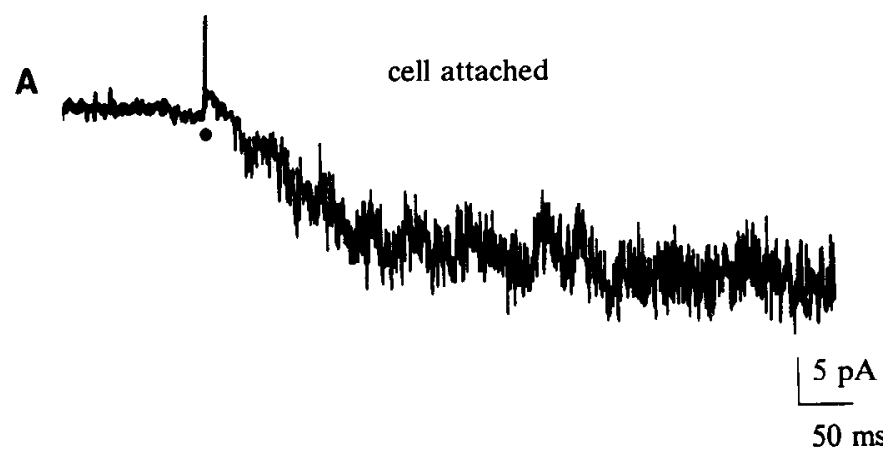

$\mathbf{B}$
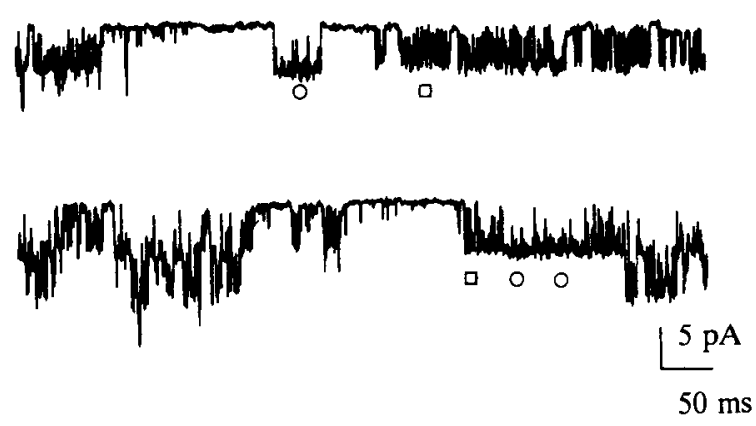

Figure 1. Pheromone-dependent currents in cultured ORNs. $A$, After application of pheromone (marked with a solid circle) to cultured ORNs (which had been in vitro at least $10 \mathrm{~d}$ ) in the cell-attached configuration (at $0 \mathrm{mV}$ holding potential), with $156 \mathrm{mM} \mathrm{KCl}$ and $10^{-7} \mathrm{M} \mathrm{Ca}^{2+}$ in the pipette, a large inward current appeared. $B$, After several minutes of washing the cell with extracellular solution, single-channel events could be resolved that showed at least three channels with superimposed openings, all reversing around $0 \mathrm{mV}$ cell potential. At least two different channel types could be distinguished according to small differences in the amplitudes, and according to the presence of subconductance states in only one of the channels present. One type of channel (circles) that showed amplitude substates resembled in its kinetics and conductance the pheromone-dependent cation channel (Fig. 2). The other channel type (squares) opened in bursts with rapid flickers between the open and closed states.

male pheromone glands or to synthetic bombykal. The cultured cells exhibited specific pheromone-evoked responses whether or not they had been exposed to the development-regulating hormone 20-hydroxyecdysone.

After application of higher concentrations of pheromone (about $1 \mathrm{ng} / \mathrm{ml}$ ), a depolarizing inward current of 35-60 pA occurred (Fig. 1A) in 23\% (11 of 48) of the pheromone-elicited responses. The current started after delays of $<100 \mathrm{msec}$ to several seconds following application of pheromone (at different distances from the cell). The duration of the inward current was at least $40 \mathrm{scc}$ while the pheromone concentration was reduced by extensive washing. In 4 of the 11 experiments in which pheromone-dependent inward current was observed, single-channel openings could be distinguished after several rinses with extracellular saline solution (Fig. 1B), which diminished the concentration of pheromone. In three cases channels could be discerned that shared properties with the cation channel described in Figure 2. These channels, with a reversal potential around $0 \mathrm{mV}$, opened in bursts and exhibited amplitude substates. In at least one case, another channel was recognized that shared properties with the previously described $\mathrm{Ca}^{2+}$-dependent $\mathrm{K}^{+}$channels (Zufall et al., 
A
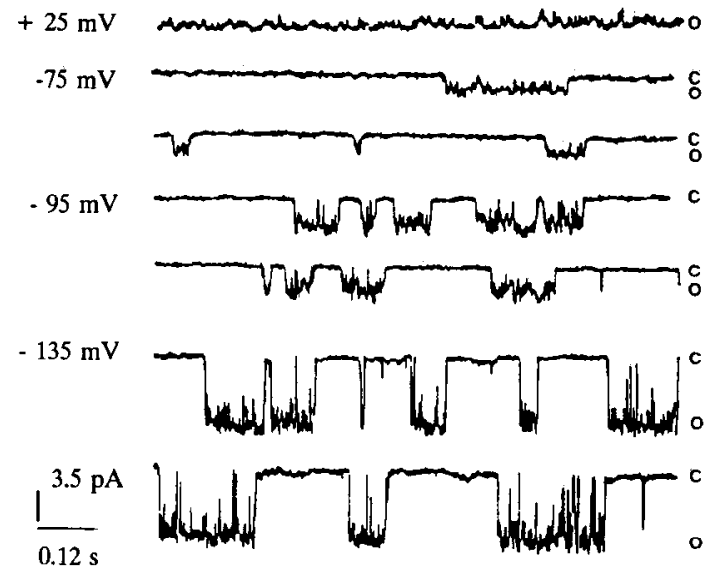

B

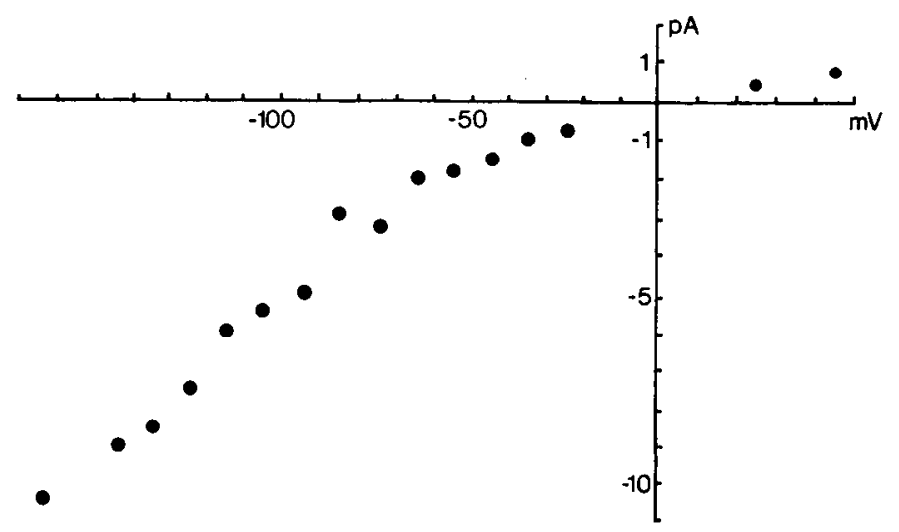

Figure 2. Cell-attached patch-clamp recording of a pheromone-dependent cation channel in a cultured ORN. A pheromone-dependent, nonspecific cation channel opened in cell-attached patches with intracellular solution containing $150 \mathrm{~mm} \mathrm{~K} \mathrm{~K}^{+}$and $10^{-7} \mathrm{M} \mathrm{Ca}^{2+}$ in the patch pipette. In $A$, single-channel openings of the cation channel are shown at different cell potentials. The channel opened in bursts and had amplitude substates. $C$, closed state; $O$, open state. $B$, The $I-V$ curve shows that the channel reversed around $0 \mathrm{mV}$. Its conductance was nonlinear, with about $20 \mathrm{pS}$ estimated at $25 \mathrm{mV}$ and $50 \mathrm{pS}$ at $-100 \mathrm{mV}$. The channel did not discriminate among $\mathrm{K}^{+}, \mathrm{Na}^{+}$, and $\mathrm{Cs}^{+}$. The ccll's membrane potential was estimated in cell-attached recordings with symmetrical $\mathrm{K}^{+}$concentrations from the reversal potential of the previously described delayed-rectifier channels (Zufall et al., 1991b) and confirmed in the current-clamp mode after establishing a whole-cell configuration. The $I-C$ curve was obtained from amplitude histograms at different pipette potentials, taking only the main amplitude state into account.

1991b). This channel opened in bursts, with rapid flickers between open and closed states, and showed no amplitude substatcs (Fig. $1 B$, squares).

After stimulation with lower concentrations of pheromone $(\mathrm{pg}-\mathrm{fg} / \mathrm{ml})$, in $54 \%$ (26 of 48 ) of the pheromone-specific responses, openings of nonspecific cation channels could be noted in single-channel records (Fig. 2A). This type of channel was never observed in cell-attached experiments in the absence of applied pheromone $(n>200)$, whereas $\mathrm{K}^{+}$channels resembling the delayed rectifier could be observed regularly. The current through the cation channels reversed around $0 \mathrm{mV}$ cell potential (i.e., between $-10 \mathrm{mV}$ and $20 \mathrm{mV}$, no channel activity was observed) in the cell-attached configuration with $\mathrm{Ca}^{2+}$-buffered

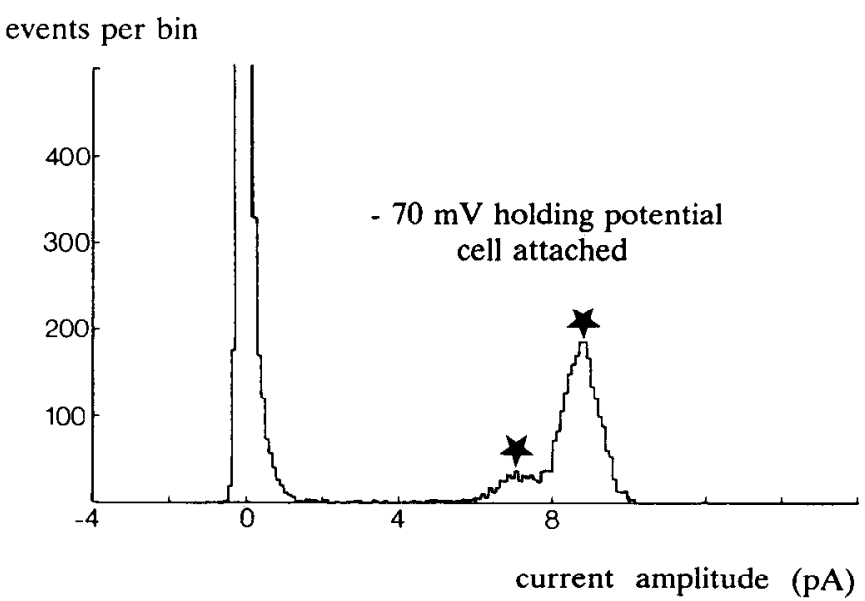

Figure 3. An amplitude histogram of pheromone-dependent cation channels in the cell-attached configuration. This amplitude histogram was prepared from the data presented in Figure 2, taken at about -70 $\mathrm{mV}$ holding potential. The peak at $0 \mathrm{pA}$ corresponds to the closed statc of the cation channels. Stars indicate different open states of about -7 $\mathrm{pA}$ (substate) and $-8.5 \mathrm{pA}$.

intracellular saline solutions containing different principal cations ( $\left(150 \mathrm{mM} \mathrm{K}^{+}, \mathrm{Na}^{+}\right.$, or $\mathrm{Cs}^{+}$) in the patch pipette (Fig. $2 B$ ). This indicated that the channels do not discriminate among $\mathrm{K}^{+}$, $\mathrm{Na}^{+}$, and $\mathrm{Cs}^{+}$. The conductance of the channels was nonlinear: circa $50 \mathrm{pS}$ at $-100 \mathrm{mV}, 36 \mathrm{pS}$ at $-25 \mathrm{mV}$, and $18 \mathrm{pS}$ at 25 $\mathrm{mV}$. Amplitude histograms at $-70 \mathrm{mV}$ holding potential revealed additional smaller-amplitude substates (Fig. 3). The burst length of channel openings (of the largest-amplitude state, at $-70 \mathrm{mV}$ holding potential) can be fitted by one exponential with a time constant of about $43 \mathrm{msec}$ (Fig. 4A). The distribution of open states of the largest-amplitude state can be described by two exponentials, with time constants of about $0.6 \mathrm{msec}$ and $2.3 \mathrm{msec}$ at $-70 \mathrm{mV}$ holding potential (Fig. $4 B$ ). The pheromone-dependent cation channel closed after prolonged (several minutes) or strong $(\mathrm{pg} / \mathrm{ml})$ pheromonal stimulation (cell attached) (see Fig. $7 B$ ).

To determine whether the pheromone opened the pheromone-dependent cation channels via mechanisms confined to the membrane, we stimulated outside-out patches with pheromone. Patch excision to the outside-out configuration, even in the absence of pheromone, activated cation channels. These cation channels reversed around $0 \mathrm{mV}$; did not discriminate among $\mathrm{Na}^{+}, \mathrm{K}^{+}$, and $\mathrm{Cs}^{+}$; and expressed conductance substates (Fig. 5). Thus, these channels closely resembled the pheromonedependent cation channels that were observed in the cell-attached configuration. The conductance of the excision-activated channels was also nonlinear, but showed less inward rectification than the pheromone-dependent cation channels. At $-100 \mathrm{mV}$ cell potential, the main conductance state of these channels was about $50 \mathrm{pS}$, while it was about $40 \mathrm{pS}$ at $-30 \mathrm{mV}$ and $37 \mathrm{pS}$ at $30 \mathrm{mV}$ (Fig. $5 B$ ). The cation channels opened readily and continuously after patch excision even in the absence of pheromone but were never observed in the cell-attached configuration under control conditions. Thus, we concentrated on cell-attached patch recordings in our search for opening of pheromone-specific ion channels.

The cation channels that were opened by patch excision were tested with a variety of substanccs in a search for agents that could close the channels. In outside-out patches, this type of 
A

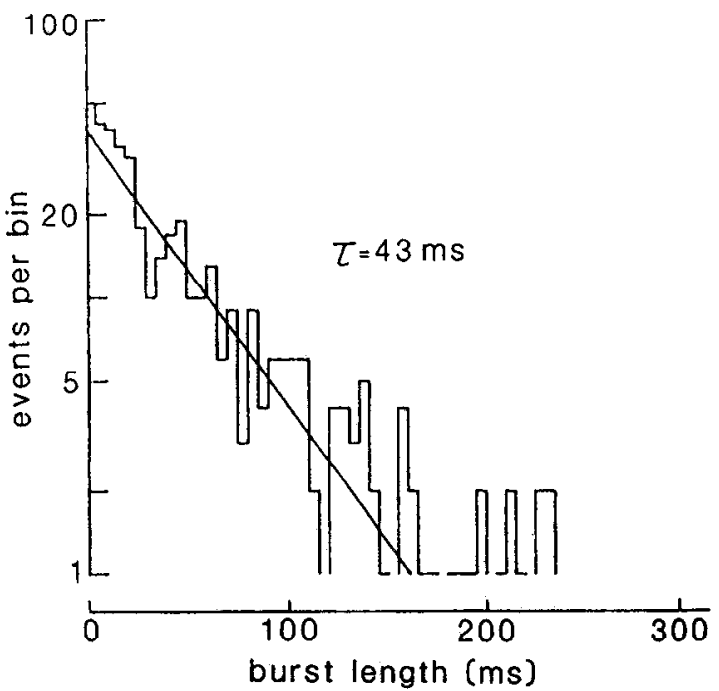

B

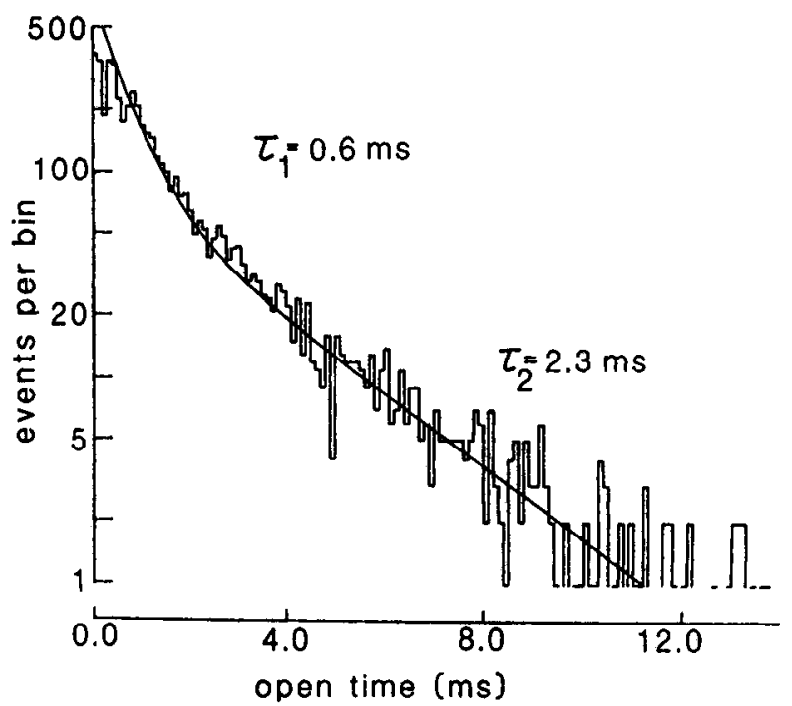

Figure 4. The burst length and the mean open-time durations of pheromone-dependent cation channels in cultured ORNs. $A$, The burst length of the nonspecific cation channel (from the same recording as in Fig. 4) at $-70 \mathrm{mV}$ holding potential can be fitted by one exponential with a time constant of $43 \mathrm{msec}$. $B$, The distribution of open times of the nonspecific cation channel at the same potential (same data as in Fig. 2 ): events with amplitudes between $-8 \mathrm{pA}$ and $-10 \mathrm{pA}$. The open times $(\tau)$ are fitted with the sum of two exponentials. The mean open times are $0.6 \mathrm{msec}$ and $2.3 \mathrm{msec}$.

channel was unaffected by $10^{-6} \mathrm{M}$ TTX, $20 \mathrm{~mm}$ 4-aminopyridine, $10 \mathrm{~mm}$ ATP, $1 \mathrm{~mm}$ bromo-cGMP, $1 \mathrm{~mm}$ bromo-cAMP, $100 \mu \mathrm{M}$ amiloride, or $\mathrm{Ca}^{2+}$-channel blockers including $\mathrm{Co}^{2+}, \mathrm{Sr}^{2+}$, and $\mathrm{Ni}^{2+}$ (applied outside). The channels were blocked in most cases by $20 \mathrm{~mm}$ tetraethylammonium chloride (applied to outside-out patches; data not shown). Replacement of $\mathrm{Cl}^{-}$by aspartate, glutamate, or acetate did not affect the currents through the cation channels, but no currents through cation channels were observed if the cations were replaced by choline.

In at least $17 \%(8 / 48)$ of the pheromone-specific responses, the previously described cGMP-blockable delayed-rectifier $\mathrm{K}^{+}$ channels (Zufall et al., 1991b) exhibited increased probability of opening after stimulation with pheromone (Fig. 6) and closed after prolonged exposure to pheromone. Because the records

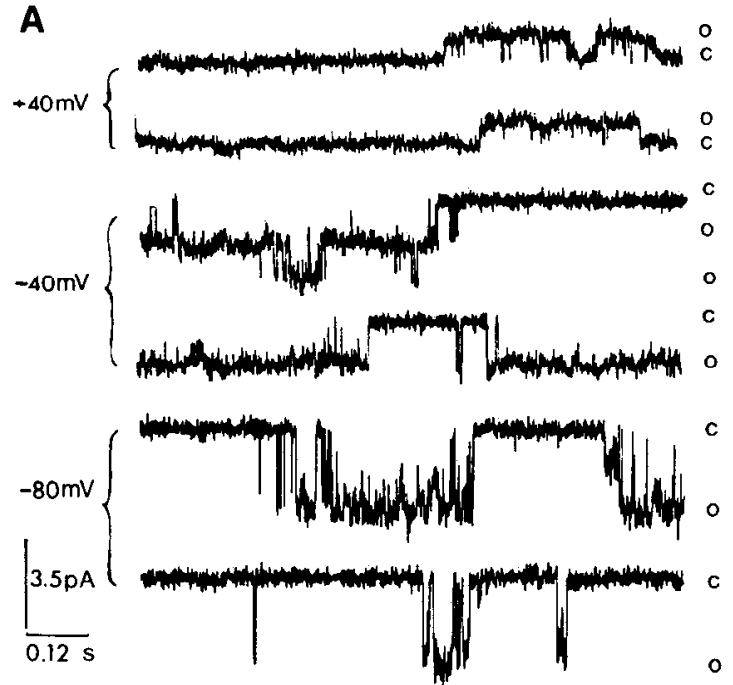

B

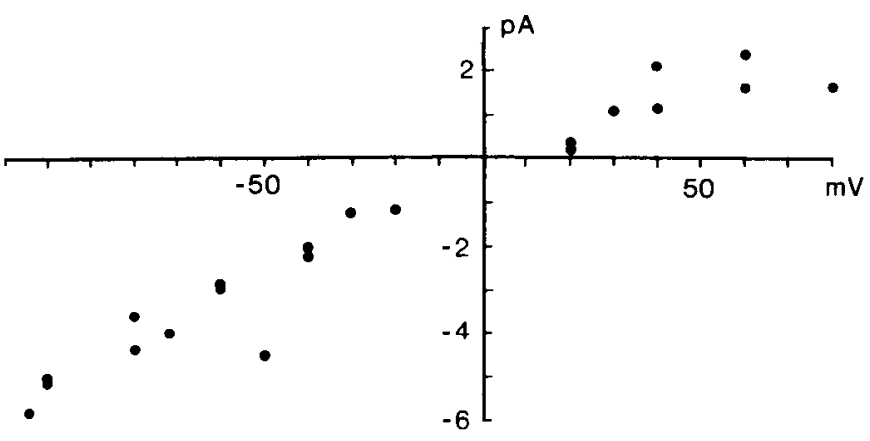

Figure 5. An outside-out patch-clamp recording of a cation channel activated by patch excision from a cultured ORN. Excision of a membrane patch to the outside-out configuration with $156 \mathrm{~mm} \mathrm{NaCl}$ outside and intracellular solution with $156 \mathrm{~mm} \mathrm{KCl}$ inside opened a nonspecific cation channel. Single-channel openings at different holding potentials $(A)$ show that the channel opened in bursts with amplitude substates ( $C$, closed state; $o$, open state of the channel). $B$, The channel reversed around $0 \mathrm{mV}$, with nonlinear conductance of about $37 \mathrm{pS}$ at $+30 \mathrm{mV}$ and about $53 \mathrm{pS}$ at $-100 \mathrm{mV}$. The channel discriminated little between $\mathrm{Na}^{+}, \mathrm{K}^{+}$, and $\mathrm{Cs}^{+}$. Thus, this excision-activated cation channel resembles the pheromone-dependent cation channel (Fig. 2).

also contained responses of several cation channels or were too short, we did not analyze them further. In at least $6 \%$ ( 3 of 48 ) of all pheromone-dependent responses, channels opened (Fig. $1 B$, squares) that resembled the previously described $\mathrm{Ca}^{2+}$-dependent $\mathrm{K}^{+}$channels (Zufall et al., 1991b) in kinetics and amplitude (data not shown).

Coapplication of PBP (Fig. 7A) was not required to obtain specific pheromone-dependent responses. After 10-60 min of incubation with high concentrations of pheromone (ca. $30 \mathrm{pg}$ / $\mathrm{ml}$ ), the pheromone-dependent cation channels and the delayedrectifier channels closed. If PBP or BSA was then applied (at a concentration of about $10 \mathrm{~mm}$ ), channels with a reversal potential of about $0 \mathrm{mV}$ opened (Fig. $7 B$ ). Channel activity that reversed around $0 \mathrm{mV}$ could be suppressed again with application of more pheromone, or thereafter elicited again with application of more $\operatorname{PBP}(n=3)$. 
cell attached patch, resting potential, high $\mathrm{K}^{+}$

control

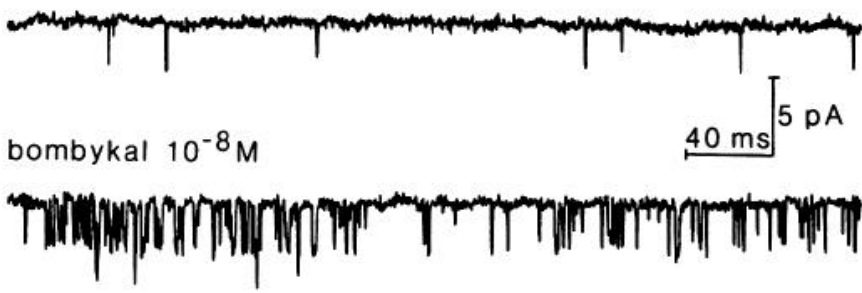

8-bromo cGMP $10^{-3} \mathrm{M}$

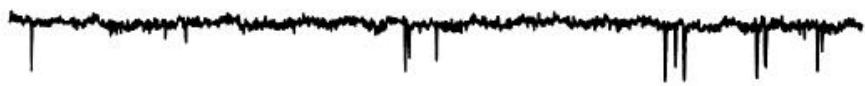

Figure 6. The nucleotide-blockable delayed rectifier $\mathrm{K}^{+}$-channels are affected by application of pheromone. The top record (control) shows delayed-rectifier channel openings in a cell-attached patch-clamp recording at the resting potential, with $150 \mathrm{mM} \mathrm{K}^{+}$in the patch pipette. The channel openings increased greatly in frequency after application of about $10^{-8} \mathrm{M}$ synthetic bombykal (second record). Application of $10^{-3}$ M bromo-cGMP blocked the delayed-rectifier activity (third record).

\section{Discussion}

The findings presented here demonstrate that cultured ORNs from male $M$. sexta antennae can respond specifically to at least one component of the species-specific sex-pheromone blend with changes in the opening of nonspecific cation channels, $\mathrm{Ca}^{2+}$ dependent $\mathrm{K}^{+}$channels, and cGMP-dependent $\mathrm{K}^{+}$channels. Furthermore, this action does not require addition of PBP.

The development of primary cell cultures of differentiating ORNs that are morphologically and immunocytochemically distinguishable (Stengl and Hildebrand, 1990) has facilitated studies of the cellular mechanisms underlying olfactory transduction. This approach now makes possible a detailed analysis of pheromone-dependent ion channels in all patch-clamp configurations, as well as in intracellular recordings, and also opens the way to molecular studies of ORNs.

Because the ORNs express different ion channels in their soma membranes at specific times in their development in vitro (Zufall et al., 1991b), we assumed that pheromone-dependent ion channels would also be expressed in their somata, before becoming localized to the dendritic sites of their final deployment. This assumption was supported by findings in other neuronal culture systems in which $\mathrm{Ca}^{2+}$ or $\mathrm{Na}^{+}$channels are first expressed in soma membranes and then became localized to the cells' processes (Fukuda and Kameyama, 1979; Roederer and Cohen, 1983). To search for pheromone-evoked responses, we recorded from soma membranes using the patch-clamp technique in the cell-attached configuration. We intended to prevent loss of cytoplasmic constituents, including second messengers that might be crucial to the mechanisms of pheromone transduction.

Female pheromone-gland extracts were chosen as the main olfactory stimuli to maximize the stimulation of all pheromonesensitive ORNs. From in vivo studies, it is known that there are at least three types of pheromone-sensitive antennal ORNs, which respond to different components of the pheromone-gland extract (Kaissling et al., 1989). To assess the specificity of the responses to the gland extract, we compared different solvent extracts, and in some of our experiments the synthetic pheromone component bombykal was employed. The similarities in the responses to bombykal and to the pheromone-gland extracts
A
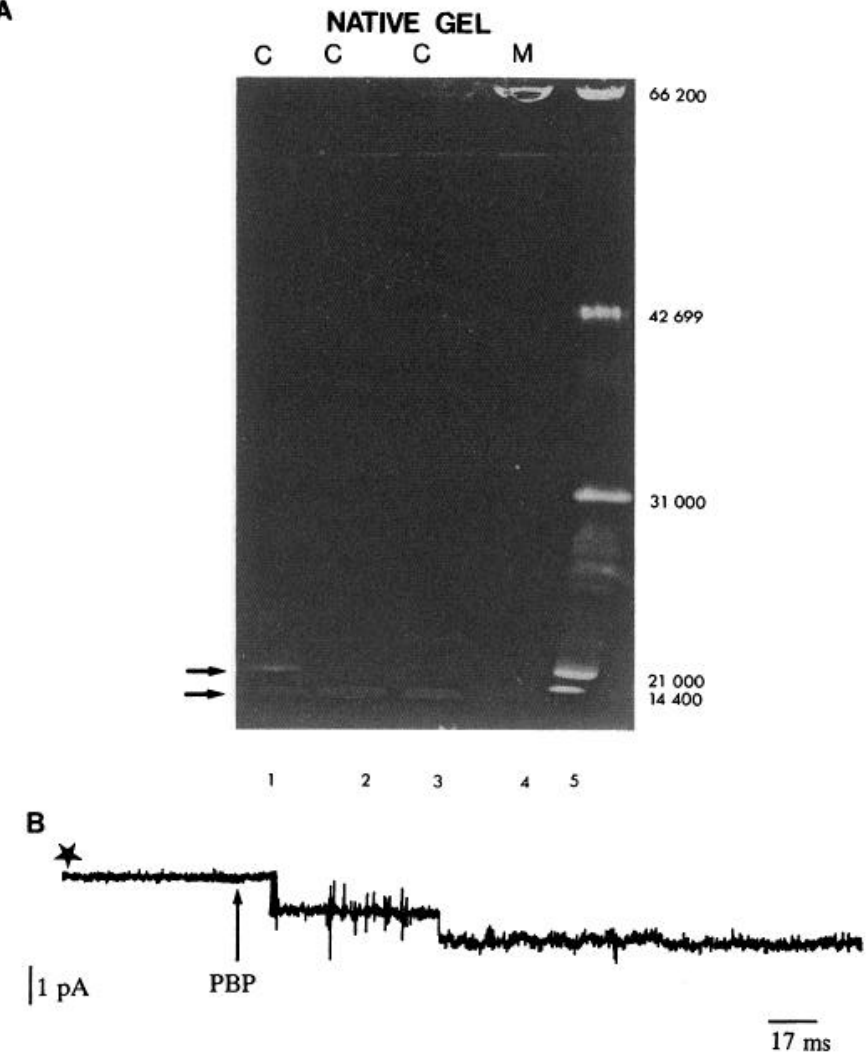

Figure 7. Preparation and testing of PBP. A, Coomassie-blue-stained native gel of protein extracts of adult male $M$. sexta antennae. Lane 5 contained molecular mass markers. Lanes 1 and 2 contained the cytoplasmic fraction $(C)$ of the sensilla and scales from two preparations, with a protein band of about $14 \mathrm{kDa}$ in lanes $I$ and 2 and an additional band of about $21 \mathrm{kDa}$ in lane 1 (arrows). These two bands between 14 and $21 \mathrm{kDa}$ of the cytoplasmic fraction of the sensilla and scales were used as "PBP" in physiological experiments. Lane 3 contained the cytoplasmic fraction of the antennal shafts and exhibits a protein band of about $14 \mathrm{kDa}$ and another between $31 \mathrm{kDa}$ and $21 \mathrm{kDa}$. Proteins of higher molecular mass remained in the stacking gel. Lane 4 was loaded with the membrane fraction $(M)$ of the antennal shafts and shows proteins of higher molecular mass that still remained in the stacking gel. $B$, After prolonged exposure to high concentrations of pheromone (ng) $\mathrm{ml}$ ), the delayed-rectifier channels as well as the nonspecific cation channels had closed (star). After subsequent application of PBP at the cell's resting potential, single-channel openings again could be observed. Two channels with a reversal potential around $0 \mathrm{mV}$ and an amplitude resembling that of the pheromone-dependent cation channel opened with very long open times.

suggest that the responses could have been due mainly or entirely to bombykal in the gland extracts. In support of this interpretation, solvents alone did not elicit any response, the pheromone concentrations used were in the physiological range (see Materials and Methods), and cells that responded to pheromone did not respond to the plant odorant citral. Moreover, the responses were specific to the ORN cell type and could be elicited only late in development in vitro. There was a good correlation between the proportion of responding cells $(38 \%)$ and the expected occurrence of pheromone-sensitive cells (35\%) among the odor-sensitive neurons (recognized on the basis of their 5 $\mu \mathrm{m}$ somata and their fine bipolar processes in vitro; Stengl and Hildebrand, 1990). Finally, we showed that cells that responded with opening of cation channels were MOSA immunoreactive. Because MOSA immunoreactivity is characteristic of male-spe- 
cific ORNs in situ (Hishinuma et al., 1988a,b), it provided further confirmation of the specificity of the responses to pheromone. Although dose-response curves usually provide further indication of response specificity, they were not determined in our experiments because we could not ascertain accurately the concentration and arrival time of the pheromonal stimulus at the cell. In a more general way, however, concentration dependence was exhibited: at higher concentrations of pheromone (picogram of bombykal), large inward currents obscured singlechannel events. Single-channel events could be resolved only after reduction of the pheromone concentration by extensive washing or addition of BSA to the medium. Even before application of the pulse of pheromone solution, diffusion of the pheromone out of the puffer pipette appeared to be sufficient to open the cation channel in cell-attached recordings. This extraordinary sensitivity is consistent with possible involvement of second-messenger cascades in the opening of the pheromonedependent cation channels. The relatively long response delays (from $<100 \mathrm{msec}$ up to several seconds) might also be accounted for by interposed second-messenger actions. Because the cultured ORNs responded to the pheromone, however, even when formation of the seal preceded delivery of the pheromonal stimulus, second-messenger control of the cation channel appears to be likely.

Considerable evidence for involvement of second-messenger systems in olfactory transduction, in vertebrates as well as in invertebrates, is accumulating (Pace et al., 1985; Nakamura and Gold, 1987; Breer et al., 1988, 1990; Firestein and Shepherd, 1989; Firestein and Werblin, 1989; Boeckhoff et al., 1990; Zufall and Hatt, 1991). After exposure to pheromone, insect ORNs exhibit relatively long-lasting increases in cGMP (Ziegelberger et al., 1990). These increases in cGMP occur in the somata rather than the dendritic regions of the ORNs. G-Protein-dependent increases of inositol 1,4,5-triphosphate $\left(\mathrm{IP}_{3}\right)$ occur in insect ORNs within milliseconds after pheromonal stimulation, but in contrast to the situation in vertebrates, no increases in cAMP could be detected (Breer et al., 1988, 1990; Boekhoff et al., 1990; Ziegelberger et al., 1990). Thus, a G-protein-dependent phospholipase C (Nishizuka, 1984; Berridge, 1987), which might cause an $\mathrm{IP}_{3}$-dependent rise in internal $\mathrm{Ca}^{2+}$, may play a role in the production of odor-dependent potential changes in insect ORNs. Furthermore, a guanylate cyclase or possibly a phosphodiesterase might be involved in the olfactory transduction mechansims. The involvement of diffusible second messengers in olfactory transduction processes thus makes it likely that channels not only in the outer dendritic segment but also in the inner dendritic segment and the soma may underlie odor-dependent potential changes that influence the firing of action potentials in ORNs. Therefore, more than one type of secondmessenger-mediated channel might be involved in the generation of the receptor potentials in ORNs.

The pheromone-dependent cation channel described here is a good candidate to be one of the second-messenger-gated channels involved in the mechanisms that underlie the depolarizing receptor potentials in pheromone-sensitive ORNs. Because this type of channel is not voltage gated and is observed only in cellattached recordings after pheromonal stimulation, its activation apparently depends upon pheromone. The opening of this channel leads to inward currents carried by $\mathrm{K}^{+}, \mathrm{Na}^{+}$, and possibly also $\mathrm{Ca}^{2+}$ at negative membrane potentials. Thus, these cation channels depolarize the cell if opened at the cell's resting potential. The suggestion that the opening of cation channels might be one of the events that underlie the pheromone-dependent generator currents is consistent with previous observations that the depolarizing receptor potentials are accompanied by a decrease in membrane resistance (Kaissling and Thorson, 1980; Kaissling, 1987). This suggestion is further supported by recent findings of pheromone-dependent, second-messenger-mediated (diacylglycerol, cGMP) cation channels on extruded dendrites of moth ORNs in situ and sccond-messenger-dependent $\left(\mathrm{Ca}^{2+}\right.$, cGMP) cation channels on dendritic segments of ORNs in $\mathrm{An}$ theraea polyphemus (Zufall and Hatt, 1991; Zufall et al., 1991a). The pheromone-dependent cation channel of cultured ORNs in $M$. sexta has a conductance different from both cation channels observed in $A$. polyphemus. Current experiments examine whether the observed pheromone-dependent cation channel in $M$. sexta, which otherwise shares reversal potential, ion selectivity, and the property of expressing multiple conductance states with both of the cation channels observed in A. polyphemus, also depends on second messengers (Stengl et al., 1991, 1992).

The $M$. sexta cation channels activated during excision of membrane patches appear not to be blockable by amyloride or cGMP, both of which block the $\mathrm{Ca}^{2+}$-dependent cation channels activated by patch excision in $A$. polyphemus. It seems likely, however, that increased $\mathrm{Ca}^{2+}$ concentrations (via influx from the extraccllular medium or damage to internal stores) during the process of patch excision activated these channels in both species. Ion channels activated by patch excision have also been found in other systems, but their functions and mechanisms of activation are unknown, although it is also assumed that $\mathrm{Ca}^{2+}$ and ATP may play a role in their activation (Yazejian and Byerly, 1989; McClintock and Ache, 1990).

Whether the cation channels activated via patch excision belong to the same type of cation channel as the pheromonedependent cation channels measured cell-attached remains to be demonstrated. Experiments in progress on $M$. sexta show that cultured ORNs are equipped with $\mathrm{Ca}^{2+}$-dependent cation channels as well as with protein kinase $\mathrm{C}$-dependent cation channels that are affected differently by cGMP (Stengl and Hildebrand, 1991; Stengl et al., 1991, in press). These data will be presented in a separate paper (M. Stengl and J. G. Hildebrand, unpublished observations). Further studies should ascertain whether the apparently different cation channels in both species of moths are truly different types of cation channels or whether they belong to the same channel type, which changes its properties via phosphorylation by protein kinases during prolonged pheromone exposure.

The opening of a channel that resembles in its kinetics and amplitude the previously described $\mathrm{Ca}^{2+}$-dependent $\mathrm{K}^{+}$channels (Zufall et al., 1991b) implies a possible increase of at least 10 -fold in internal $\mathrm{Ca}^{2+}$ after application of pheromone. The observed changes in the probability of opening of the nucleotidesensitive delayed-rectifier $\mathrm{K}^{+}$channels could possibly be accounted for by changes in the levels of ATP or cGMP or by changes in the cell's potential (Zufall et al., 1991b). Because increases in cGMP after pheromonal stimulation have been found in insect ORNs (Ziegelberger et al., 1990), the closing of the delayed-rectifier $\mathrm{K}^{+}$channel after prolonged cxposurc to pheromone might be caused by cGMP. Because the current amplitude of the delayed rectifier did not decrease in all recordings, the pheromone-dependent increase in activity is probably not caused by a depolarization of the ORN.

In view of the fact that application of PBP was not necessary to obtain pheromone-dependent responses in cultured ORNs 
as well as in recent in situ experiments (Zufall and Hatt, 1991), it seems that the pheromone need not be presented in the form of a pheromone-PBP complex to a presumptive receptor site. We cannot exclude the possibility, however, that PBP might have been produced in vitro and therefore present in cultured ORNs in a membrane-bound form in which it was not washed away by superfusion. The PBP could be used interchangeably with BSA (which unspecifically binds lipophilic substances), apparently reducing pheromone concentrations and thus possibly preventing channel closure. Thus, our preliminary results are consistent with the possibility that PBP may also serve to scavenge the pheromone and hence to prevent adaptation due to overstimulation by pheromone. However, this study did not attempt to analyze the function of the PBP. The influence of the PBP on the time course and adaptation of the response to pheromone remains to be investigated further.

\section{References}

Bell RA, Joachim FA (1976) Techniques for rearing laboratory colonies of tobacco hornworms and pink bollworms. Ann Entomol Soc Am 69:365-373.

Berridge MJ (1987) Inositol triphosphate and diacylglycerol: two interacting second messengers. Annu Rev Biochem 56:159-193.

Boekhoff I, Strotmann J, Raming K, Tareilus E, Breer H (1990) Odorant-sensitive phospholipase $\mathrm{C}$ in insect antennae. Cell Signaling 2: 49-56.

Breer H, Raming K, Boekhoff I (1988) G-proteins in the antennae of insects. Naturwissenschaften 75:627.

Breer H, Boekhoff I, Tareilus E (1990) Rapid kinetics of second messenger formation in olfactory transduction. Nature 345:65-68.

Christensen TA, Hildebrand JG, Tumlinson JH, Doolittle RE (1989) Sex pheromone blend of Manduca sexta: responses of central olfactory interneurons to antennal stimulation in male moths. Arch Insect Biochem Physiol 10:281-291.

Dudel J, Franke C (1987) Single glutamate-gated synaptic channels at the crayfish neuromuscular junction. II. Dependence of channel open time on glutamate concentration. Pfluegers Arch 408:307-314.

Eaton JL (1986) Morphology of abdominal segments eight and nine of the female tobacco hornworm Manduca sexta (Lepidoptera: Sphingidae). Ann Entomol Soc Am 79:629-635.

Firestein S, Shepherd GM (1989) Olfactory transduction is mediated by the direct action of cAMP. Soc Neurosci Abstr 15:768.

Firestein S, Werblin F (1989) Odor-induced membrane currents in vertebrate-olfactory receptor neurons. Science 244:79-82.

Fukuda J, Kameyama M (1979) Enhancement of $\mathrm{Ca}^{2+}$ spikes in nerve cells of adult mammals during neurite growth in tissue culture. Nature 279:546-548.

Grünert U (1985) Cuticulare Dehnungsrezeptoren von Insekten und Spinnen: Analyse der Rezeptorlymphe. PhD Dissertation, Universität Frankfurt, Germany.

Györgyi TK, Roby-Shemkovitz AJ, Lerner MR (1988) Characterization and cDNA cloning of the pheromone-binding protein from the tobacco hornworm, Manduca sexta: a tissue-specific developmentally regulated protein. Proc Natl Acad Sci USA 85:9851-9855.

Hamill OP, Marty A, Neher E, Sakmann B, Sigworth FJ (1981) Improved patch-clamp techniques for high resolution current recordings from cells and cell free membrane patches. Pfluegers Arch 391:85100.

Hishinuma A, Hockfield S, McKay R, Hildebrand JG (1988a) Monoclonal antibodies reveal cell-type-specific antigens in the sexually dimorphic olfactory system of Manduca sexta. I. Generation of monoclonal antibodies and partial characterization of the antigens. J Neurosci $8: 296-307$

Hishinuma A, Hockfield S, McKay R, Hildebrand JG (1988b) Monoclonal antibodies reveal cell-type-specific antigens in the sexually dimorphic olfactory system of Manduca sexta. II. Expression of antigens during postembryonic development. J Neurosci 8:308-315.

Itagaki H, Conner WE (1988) Calling behavior of Manduca sexta (L.) (Lepidoptera: Sphingidae) with notes on the morphology of the female sex pheromone gland. Ann Entomol Soc Am 81:798-807.
Kaissling K-E (1986) Chemo-electrical transduction in insect olfactory receptors. Annu Rev Neurosci 9:121-145.

Kaissling K-E (1987) RH Wright lectures on insect olfaction (Colbow K, ed). Burnaby, British Columbia, Canada: Simon Fraser University.

Kaissling K-E, Thorson J (1980) Insect olfactory sensilla: structural, chemical and electrical aspects of the functional organization. In: Receptors for neurotransmitters, hormones and pheromones in insects (Sattelle DB, Hall LM, Hildebrand JG, eds), pp 261-282. Amsterdam: North-Holland/Elsevier.

Kaissling K-E, Klein U, DeKramer JJ, Keil TA, Kanaujia S, Hemberger J (1985) Insect olfactory cells: electrophysiological and biochemical studies. In: Molecular basis of nerve activity (Changeux JP, Hucho F, Maelicke A, Neumann E, eds), pp 173-183. Berlin: Walter de Gruyter.

Kaissling K-E, Zack Strausfeld C, Rumbo E (1987) Adaptation processes in insect olfactory receptors: mechanisms and behavioral significance. Ann NY Acad Sci 510:104-112.

Kaissling K-E, Hildebrand JG, Tumlinson JH (1989) Pheromone receptor cells in the male moth Manduca sexta. Arch Insect Biochem Physiol 10:273-279.

Keil TA (1984) Reconstruction and morphometry of silkmoth olfactory hairs: a comparative study of sensilla trichodea on the antennae of male Antheraea polyphemus and Antheraea pernyi (Insecta, Lepidoptera). Zoomorphology (Berl) 104:147-156.

Keil TA (1989) Fine structure of the pheromone-sensitive sensilla on the antenna of the hawkmoth, Manduca sexta. Tissue Cell 21:139151 .

Klein U (1987) Sensillum-lymph proteins from antennal olfactory hairs of the moth Antheraea polyphemus (Saturniidae). Insect Biochem 17:1193-1204.

Lee JK, Strausfeld NJ (1990) Structure, distribution, and number of surface sensilla and their receptor cells on the antennal flagellum of the male sphinx moth Manduca sexta. J Neurocytol 19:519-538.

McClintock TS, Ache B (1990) Nonselective cation channel activated by patch excision from lobster olfactory receptor neurons. J Membr Biol 113:115-122.

Nakamura T, Gold G (1987) A cyclic nucleotide-gated conductance in olfactory receptor cilia. Nature 325:442-443.

Nishizuka $Y(1984)$ The role of protein kinase $C$ in cell surface signal transduction and tumour promotion. Nature 308:693-697.

Pace U, Hanski E, Salomon Y, Lancet D (1985) Odorant-sensitive adenylate cyclase may mediate olfactory reception. Nature 316:255258.

Peterson GL (1977) A modified Lowry assay. Anal Biochem 83:346356.

Raming K, Krieger J, Breer H (1989) Molecular cloning of an insect pheromone-binding protein. FEBS Lett 256:215-218.

Raming K, Krieger J, Breer H (1990) Primary structure of a pheromone binding protein from Antheraea pernyi: homologies with other ligand-carrying proteins. J Comp Physiol B 160:503-509.

Roederer E, Cohen MJ (1983) Regeneration of an identified central neuron in the cricket. II. Electrical and morphological responses of the soma. J Neurosci 3:1848-1859.

Sanes JR, Hildebrand JG (1976a) Structure and development of antennae in a moth, Manduca sexta. Dev Biol 51:282-299.

Sanes JR, Hildebrand JG (1976b) Origin and morphogenesis of sensory neurons in an insect antenna. Dev Biol 51:300-319.

Schneider D (1962) Electrophysiological investigation of insect olfaction. In: Olfaction and taste (Zottermann IY, ed), pp 85-103. Oxford: Pergamon.

Schneider D, Boeckh J (1962) Rezeptorpotential und Nervimpulse einzelner olfaktorischer Sensillen der Insektenantenne. Z Vgl Physiol 45:405-412.

Schweitzer ES, Sanes JR, Hildebrand JG (1976) Ontogeny of electroantennogram responses in the moth Manduca sexta. J Insect Physiol 22:955-960.

Starratt AN, Dahm KH, Allen N, Hildebrand JG, Payne TL, Röller H (1979) Bombykal, a sex pheromone of the sphinx moth Manduca sexta. Z Naturforsch 34:9-12.

Stengl M, Hildebrand JG (1990) Insect olfactory receptor neurons in vitro: morphological and immunocytochemical characterization of male specific-antennal receptor cells from developing antennae of male Manduca sexta. J Neurosci 10:837-847.

Stengl M, Hildebrand JG (1991) Patch clamp studies on second-messenger-mediated calcium regulation in cultured insect olfactory re- 
ceptor neurons. In: Synapse-transmission-modulation (Elsner N, Penzlin H, eds), p 23. Stuttgart: Thieme.

Stengl M, Zufall F, Hatt H, Dudel J, Hildebrand JG (1989) Patch clamp analysis of male Manduca sexta olfactory receptor neurons in primary cell culture. Soc Neurosci Abstr 15:751.

Stengl M, Levine RB, Hildebrand JG (1991) Olfactory receptor neurons of the male moth Manduca sexta express second messenger modulated ion channels in vitro. Soc Neurosci Abstr 17:1102.

Stengl M, Hatt H, Breer H (1992) Peripheral processes in insect olfaction. Annu Rev Physiol, 54:665-681.

Tolbert LP, Matsumoto SG, Hildebrand JG (1983) Development of synapses in the antennal lobes of the moth Manduca sexta during metamorphosis. J Neurosci 3:1158-1175.

Tumlinson JH, Brennan MM, Doolittle RE, Mitchell ER, Brabham A, Mazomenos BE, Baumhover AH, Jackson DM (1989) Identification of a pheromone blend attractive to Manduca sexta (L.) males in a wind tunnel. Arch Insect Biochem Physiol 10:255-271.

van den Berg MJ, Ziegelberger G (1991) On the function of the pheromone binding protein in the olfactory hairs of Antheraea polyphemus. J Insect Physiol 37:79-85.

Vogt RG (1987) The molecular basis of pheromone reception: its influence on behavior. In: Pheromone biochemistry (Prestwich GD, Blomquist GJ, eds), pp 385-431. New York: Academic.

Vogt RG, Riddiford LM (1981) Pheromone binding and inactivation by moth antennae. Nature 293:161-163.
Vogt RG, Riddiford LM, Prestwich GD (1985) Kinetic properties of a pheromone degrading enzyme: the sensillar esterase of Antheraea polyphemus. Proc Natl Acad Sci USA 82:8827-8831.

Yazejian B, Byerly L (1989) Voltage-independent, barium-permcable channel activated in Lymnaea neurons by internal perfusion or patch excision. J Membr Biol 107:63-76.

Zack-Strausfeld C (1979) Sensory adaptation in the sex pheromone receptor cells of Saturniid moths. PhD Dissertation, Ludwig Maximilians Universität, München, Germany.

Zack-Strausfeld C, Kaissling K-E (1986) Localized adaptation processes in olfactory sensilla of Saturniid moth. Chem Senses 11:499512.

Ziegelberger G, van den Berg MJ, Kaissling K-E, Klumpp S, Schultz JE (1990) Cyclic GMP levels and guanylate cyclase activity in pheromone-sensitive antennae of the silkmoths Antheraea polyphemus and Bombyx mori. J Neurosci 10:1217-1225.

Zufall F, Hatt H (1991) Dual activation of a sex pheromone-dependent ion channel from insect olfactory dendrites by protein kinase $\mathrm{C}$ activators and cyclic GMP. Proc Natl Acad Sci USA 88:8520-8524.

Zufall F, Hatt H, Keil TA (1991a) A calcium-activated nonspecific cation channel from olfactory receptor neurones of the silkmoth $\mathrm{An}$ theraea polyphemus. J Exp Biol, 161:455-468.

Zufall F, Stengl M, Franke C, Hildebrand JG, Hatt H (1991b) Ionic currents of cultured olfactory receptor neurons from antennae of male Manduca sexta. J Neurosci 11:956-965. 